\title{
Psychological Impact of COVID-19, Isolation, and Quarantine: A Cross-Sectional Study
}

\author{
Ghufran Jassim (D)' \\ Mariam Jameel ${ }^{2}$ \\ Edwina Brennan ${ }^{3}$ \\ Manaf Yusuf ${ }^{3}$ \\ Nebras Hasan ${ }^{3}$ \\ Yusuf Alwatani ${ }^{4}$ \\ 'Family Medicine Department, Royal \\ College of Surgeons in Ireland - Medical \\ University of Bahrain (RCSI Bahrain), \\ Busaiteen, Bahrain; ${ }^{2}$ Department of \\ Medicine, Salmaniya Medical Complex, \\ Manama, Bahrain; ${ }^{3} \mathrm{RCSI}$, Busaiteen, \\ Bahrain; ${ }^{4}$ Psychiatry Department, Serene \\ Psychiatry Hospital, Manama, Bahrain
}

Purpose: The COVID-19 pandemic has resulted in mandatory isolation and quarantine. The objective of this study was to describe and compare the psychological impacts of COVID-19 isolation and quarantine.

Methods: This was a cross-sectional retrospective study. Participants were Bahrainis aged $>18$ years who had undergone either isolation or quarantine. Eligible participants were identified from the COVID-19 contacts (quarantine) and cases (isolation) database of Bahrain. Validated questionnaires for self-reported depression (Center for Epidemiological Studies - depression [CES-D]), posttraumatic stress (Impact of Event Scale — revised [IES-R]), and perceived stigma (Stigma Scale [SS]) were administered.

Results: Mean CES-D, IES-R, and SS scores were 16.76 $\pm 5.65,13.50 \pm 14.67$, and 25.29 \pm 7.99 , respectively. In sum, $40 \%$ (205 of 502) of participants showed clinically significant depression, and $<20 \%$ (98 of 502) had indications of some posttraumatic distress, with greater depression and distress in those isolated than those quarantined. Perceived stigma was reported by $53.4 \%$ (268 of 502) of participants, more prominent among those quarantined. Depression and posttraumatic stress scores were significantly higher in females, college students, those with a history of mental health conditions, knowing a COVID-19 fatality, and experiencing social conflict. Age was a significant variable correlated with all three scales, with younger participants indicating more distress, depression, and stigma. Duration of segregation was significantly correlated with CES-D, score showing more depressive symptoms as the duration of isolation increased. Significant predictors were age, sex, history of mental illness, and COVID-19 status.

Conclusion: Isolated and quarantined individuals reported depression, perceived stigma, and to a lesser extent distress. Psychological interventions identifying and targeting people with different-severity psychological burdens are in urgent need.

Keywords: COVID-19, psychological impact, isolation, quarantine, Bahrain

\section{Introduction}

On 30 January 30, 2020, the WHO director-general declared COVID-19 a public health emergency of international concern. To prevent the spread of the virus, individuals testing positive for the disease should be placed in isolation, ("separation of ill or infected persons from others"). ${ }^{1}$ Discharge required clinical recovery with two negative sequential RT-PCR results within 24 hours, which was later updated to 10 days after symptom onset plus a minimum of 3 days without symptoms for symptomatic patients and 10 days after a positive test for asymptomatic patients. ${ }^{2}$ In addition to isolation, quarantine ("separation of persons who are not ill, but who may have been exposed to an infectious agent or disease"), ${ }^{1}$
Correspondence: Ghufran Jassim Family Medicine Department, Royal College of Surgeons in Ireland — Medical University of Bahrain (RCSI Bahrain), PO Box I5503, Adliya-Bahrain, Busaiteen, Bahrain

Tel +973 39-680-009

Email gjassim@rcsi-mub.com 
measures were introduced. Individuals identified as contacts (eg, providing direct care without the use of personal protective equipment, having face-to face-contact within $1 \mathrm{~m}>15$ minutes) of laboratory-confirmed cases required 14 days of quarantine from the last time they were exposed to the patient. ${ }^{3}$

Although isolation and quarantine have distinct meanings in practice, they both involve the separation of an individual from their loved ones, normal activities, and routines for the purpose of infection prevention. The psychological impact of quarantine and isolation was exacerbated by the harmful effect of limited physical activity and changes in dietary practices. ${ }^{4}$ Such changes may result in dramatic and long-lasting psychological impact. A study on quarantined and isolated individuals with severe acute respiratory syndrome (SARS) and $\mathrm{H} 1 \mathrm{~N} 1$ reported posttraumatic stress symptoms, confusion, and anger. Stressors included longer quarantine, infection fears, frustration, boredom, inadequate supplies, inadequate information, financial loss, and stigma. ${ }^{5}$ In a study on health-care workers who had survived the Middle East respiratory syndrome coronavirus (MERS-CoV) epidemic in Saudi Arabia in 2015, participants explained a variety of painful experiences of rejection and avoidance by their colleagues and neighbors postrecovery. ${ }^{6}$ Similar avoidance was reported by SARS survivors, along with perceived barriers to service access and employment ${ }^{7}$ and well beyond the initial outbreak. ${ }^{8}$ Stigma, including being shunned, insulted, marginalized, and rejected in the domains of work, interpersonal relationships, use of services, and schooling was also reported. ${ }^{9}$ In the context of the current pandemic, reports from China have showed rates of up to $30 \%$ for anxiety, ${ }^{10} 17 \%$ depression, ${ }^{11}$ and $35 \%$ traumarelated distress symptoms. ${ }^{12}$ Similar rates have also been reported in Italy following implementation of lockdown measures. $^{13}$ Furthermore, reports from India and Bangladesh have described suicidal behaviors (eg, suicidal ideation, suicide attempts, and actual suicide) for various reasons. $^{14,15}$

In the context of the current COVID-19 outbreak, the Bahraini containment strategy includes the rapid identification of laboratory-confirmed cases, isolation, and management. In parallel, comprehensive contact-tracing measures are conducted using the BeAware Bahrain app, which notifies individuals of close contact with suspected cases, facilitates COVID-19 testing, enables close vigilance of self-isolation/quarantine, and provides relevant and accurate information from a reputable source. ${ }^{16}$ The containment strategy includes the International COVID-19 Repatriation Programme, with repatriates clinically segregated from the general population to complete quarantine and testing before being formally admitted to the country. ${ }^{2}$ The objective of this study was to describe and compare the psychological effects of COVID-19 between those placed into isolation and those placed into quarantine.

\section{Methods}

\section{Study Design and Participants}

This was a cross-sectional retrospective study. Participants were Bahrainis aged $>18$ years who had undergone either isolation or quarantine. Eligible participants were identified from the COVID-19 contacts (quarantine) and cases (isolation) database of Bahrain. Two groups of participants were identified and recruited: "early", which comprised the first confirmed cases diagnosed between February 24 and March 20, 2020, and "late", which included all cases and contacts diagnosed August 1-5, 2020. We included all patients registered in the database if they fit the inclusion criteria. Trained medical residents conducted the survey via telephone in August 2020. Participation was voluntary and participant data anonymized.

\section{Outcomes}

We used three scales to assess the psychological impact of participants, which specifically focused on depression, posttraumatic stress, and perceived stigma. The Center for Epidemiological Studies - depression (CES-D) Scale $^{17}$ was used as a measure of any depressive symptoms as a result of COVID-19 isolation or quarantine. This scale is composed of 20 self-report items, each on a Likert scale of $0-3$. Possible scores are $0-60$. A score $>16$ has been shown to identify persons with depressive symptoms similar in severity to levels observed among depressed patients. ${ }^{17,18}$ The higher the score, the greater the presence of more symptomatology.

To assess post-traumatic stress, the Impact of Event Scale - revised (IES-R) ${ }^{19}$ was employed. This is a selfreport measure designed to assess distress resulting from a traumatic life event and is composed of 22 items, each on a Likert scale of $0-4$ ( 0 not at all, 1 a little bit, 2 moderate, 3 quite a bit, 4 extreme). The maximum score is 88. A score of 24-32 indicates clinical concern for posttraumatic stress disorder (PTSD). Those with scores this high who do not have full PTSD will have partial PTSD or at least some of the symptoms. ${ }^{20}$ A score of $33-38$ is the cutoff for probable diagnosis of PTSD, ${ }^{21}$ 
and $\geq 39$ enough to suppress the immune system's functioning, even 10 years after an impact event. ${ }^{22}$

The Stigma Scale (SS) 20 was used to examine perceived stigma because of isolation or quarantine. This 15item scale uses a four-point Likert scale from strongly disagree (0) strongly agree (3). It assesses the key causes (fear of casual transmission, willingness to interact with affected individuals, and moral values of blame, shame, responsibility, guilt, punishment, and judgment) and consequences (negative feelings and emotional reactions toward affected individuals, isolation, discrimination, and disclosure) of stigma. ${ }^{23}$ Participants are classified as having/not having perceived stigma using the mean of the stigma variable as the cutoff point. Designed for tuberculosis, the scale was adapted in this study to the sociocultural context of Bahrain and COVID-19.

These scales are widely used, and have been translated into many different languages, including Arabic. The reliability and validity of the CES-D and IES-R have been demonstrated in previous research for various languages, including Arabic. ${ }^{24,25}$ Cronbach's $\alpha$ coefficient was used to test the reliability and internal consistency of the scales in this study.

\section{Statistical Analysis}

Descriptive and inferential analyses were conducted, and means $\pm \mathrm{SD}$ ) are presented for continuous data and $\mathrm{n}(\%)$ for categorical data for all participants, isolated and quarantined. Overall IES-R, CES-D, and SS scores are reported as means \pm SD for each scale band for all participants, and for COVID-19 status, (isolated and quarantined). CES-D scores are split into $>16$ and $\leq 16$. IES-R scores are grouped as $<24,24-32,33-38$, and $\geq 39$. For the SS, negative items were reverse-scored, then standardized scores of $0-50$ obtained from the raw scores using the formula $\left(\mathrm{SS}_{\text {raw }} \times 50\right) /(\mathrm{n} \times 3)$, where $\mathrm{n}$ is the number of items in the scale and 3 the maximum score per item. Normality tests were used to determine if the data set were well modeled by a normal distribution, and as a result parametric testing was used. ANOVA and independent $t$-tests were used to compare means where appropriate. Pearson's correlation coefficient was used to test the association between continuous variables. $P<0.05$ was considered indicate statistically significant. Multivariate linear regression analysis was used to access predictors of IES-R, CES$\mathrm{D}$, and SS scores.

\section{Results}

Of 1,106 eligible subjects, 502 responded and consented to participation, 24 refused, 436 did not answer or had invalid contact numbers, and 144 did not meet the inclusion criteria. The mean age of participants was $40 \pm 14.71$ years, half were female $(50.2 \%, 252$ of 502$)$, most married $(78.5 \%, 394$ of $502)$, most had high school education or above $(81.9 \%, 411$ of 502), approximately a third unemployed $(33.7 \%, 169$ of 502 ), $20.7 \%$ (116 of 502)employed in the public sector, and $23.1 \%$ (104 of 502) employed in the private sector (Table 1). Mean duration of segregation for all participants was 18.06 \pm 14.00 and $22.25 \pm 16.40$ days for those in isolation, and $11.79 \pm 4.67$ days for those in quarantine. In sum, $72.7 \%$ (365 of 502) of all participants were nonsmokers, and $44.6 \%$ (224 of 502) had comorbidities. Less than 3\% (14 of 502 ) had a history of mental conditions.

The mean CES-D score for all participants was 16.76 \pm 5.65 : $40.8 \%$ (205 of 502 ) scored $>16$, a score shown to identify persons with depressive symptoms similar in severity to levels observed among depressed patients, while $45.50 \%$ (137 of 301 ) of participants who were isolated met the cutoff of $\geq 16$ or more compared to $33.8 \%$ (68 of 201 ) of participants quarantined (Table 2). The mean IES-R score for all participants was $13.50 \pm 14.67$, with $19.6 \%$ (98 of 502) scoring $\geq 24$, indicating minimum clinical concern for 17. The mean SS score for all participants was 25.29 \pm 7.99 , with $53.4 \%$ (268 of 502 ) scoring above the determined cutoff ( $>25)$. More than $60 \%$ (129 of 201) of participants quarantined exceeded the cutoff compared to $46 \%$ of those placed in isolation (Table 2). Demographic variables that had statistically significant associations with CES-D score were sex and occupation. IES-R scores were significant for sex, occupation, and education. Education was also significantly associated with SS scores (Table 3).

Clinical variables that had statistically significant associations with CES-D scores were smoking status, history of mental conditions, place of segregation, transmitting the infection to another person, having difficulty returning to work, experiencing social conflict, knowing someone who had died due to COVID-19, and COVID-19 status (Table 4). For IES-R scores, significant variables were history of mental conditions, experiencing social conflict, and knowing someone who had died due to COVID-19. Variables that were statistically significantly associated with SS scores were place of segregation, transmitting the infection to someone else, experiencing social conflict, and COVID-19 status. 
Table I Demographics and clinical data for participants and COVID-19 status: isolated and quarantined

\begin{tabular}{|c|c|c|c|c|c|}
\hline & & $\begin{array}{c}\text { Total }(n=502) \\
n(\%)\end{array}$ & $\begin{array}{c}\text { Isolated }(\mathrm{n}=\mathbf{3 0} \mathrm{I}) \\
\mathrm{n}(\%)\end{array}$ & $\begin{array}{c}\text { Quarantined }(n=20 I) \\
n(\%)\end{array}$ & $\mathbf{P}$ \\
\hline \multicolumn{2}{|l|}{ Age, mean (SD) } & $40.4 I(14.47)$ & $41.10(14.64)$ & $39.36(14.18)$ & 0.187 \\
\hline \multicolumn{2}{|c|}{ Duration of segregation (days), mean (SD) } & $18.06(14)$ & $22.25(16.4)$ & $11.79(4.67)$ & $<0.001$ \\
\hline \multirow[t]{2}{*}{ Sex } & Females & $252(50.2 \%)$ & $|5|(50.2 \%)$ & $101(50.2 \%)$ & \multirow[t]{2}{*}{0.986} \\
\hline & Males & $250(49.8 \%)$ & 150 (49.8\%) & $100(49.8 \%)$ & \\
\hline \multirow[t]{4}{*}{ Marital Status } & Single & $93(18.5 \%)$ & $54(17.9 \%)$ & 39 (19.4\%) & \multirow[t]{4}{*}{0.975} \\
\hline & Married & $394(78.5 \%)$ & $238(79.1 \%)$ & $156(77.6 \%)$ & \\
\hline & Divorced & $7(1.4 \%)$ & $4(1.3 \%)$ & $3(1.5 \%)$ & \\
\hline & Widowed & $8(1.6 \%)$ & $5(1.7 \%)$ & $3(1.5 \%)$ & \\
\hline \multirow[t]{5}{*}{ Education } & Elementary or below & $22(4.4 \%)$ & $15(4 \%)$ & 7 (3.5\%) & \multirow[t]{5}{*}{0.204} \\
\hline & Middle & $69(13.7 \%)$ & $42(14 \%)$ & 27 (13.4\%) & \\
\hline & High & 195 (38.8\%) & $126(41.9 \%)$ & $69(34.3 \%)$ & \\
\hline & Undergraduate & 159 (31.7\%) & 90 (29.9\%) & 69 (34.3\%) & \\
\hline & Postgraduate & 57 (II.4\%) & $28(9.3 \%)$ & $29(14.4 \%)$ & \\
\hline \multirow[t]{6}{*}{ Occupation } & Retired & 93 (I8.5\%) & $58(19.3 \%)$ & 35 (I7.4\%) & \multirow[t]{6}{*}{0.289} \\
\hline & Employed (public) & $116(23.1 \%)$ & 60 (19.9\%) & $56(27.9 \%)$ & \\
\hline & Employed (private) & $104(20.7 \%)$ & $62(20.6 \%)$ & 42 (20.9\%) & \\
\hline & Self-employed & $14(2.8 \%)$ & II (3.7\%) & $3(1.5 \%)$ & \\
\hline & Unemployed & 169 (33.7\%) & $106(35.2 \%)$ & $63(31.3 \%)$ & \\
\hline & Student & $6(1.2 \%)$ & $4(1.3 \%)$ & $2(1 \%)$ & \\
\hline \multirow[t]{3}{*}{ Smoking status } & Smoker & 98 (19.5\%) & $55(18.3 \%)$ & $43(21.4 \%)$ & \multirow[t]{3}{*}{0.135} \\
\hline & Nonsmoker & $365(72.7 \%)$ & $217(72.1 \%)$ & 148 (73.6\%) & \\
\hline & Ex-smoker & $39(7.8 \%)$ & $29(9.6 \%)$ & $10(5 \%)$ & \\
\hline \multirow[t]{2}{*}{ Comorbidities } & Yes & 224 (44.6\%) & I34 (44.5\%) & $90(44.8 \%)$ & \multirow[t]{2}{*}{0.955} \\
\hline & No & 278 (55.4\%) & $167(55.5 \%)$ & III (55.2\%) & \\
\hline \multirow{2}{*}{$\begin{array}{l}\text { History of mental } \\
\text { conditions }\end{array}$} & Yes & $14(2.8 \%)$ & $9(3 \%)$ & 5 (2.5\%) & \multirow[t]{2}{*}{0.738} \\
\hline & No & 488 (97.2\%) & $292(97 \%)$ & 196 (97.5\%) & \\
\hline
\end{tabular}

Age was a significant variable correlated with all three scales, with younger participants displaying greater distress, depression, and stigma (Table 5). Duration of segregation was significantly correlated with CES-D scores, with more depressive symptoms as the duration of isolation increased. Multivariate linear regression analysis was used to test if demographics and clinical variables significantly predicted CES-D, IES-R, and SS scores (Table 6). Results indicated that they explained $11.4 \%$ of the variance in CES-D scores. Significant predictors were age, sex, history of mental illness, and COVID-19 status. Further, predictors explained 8.6\% and $4.6 \%$ of variations in IES-R and SS scores, respectively.

Reliability of the CES-D, IES-R, and SS was tested, and showed Cronbach's $\alpha=0.72,0.90$, and 0.83 respectively. 
Table 2 Mean of CES-D, IES-R, and SS scores for all participants by COVID-I 9 status: isolated and quarantined

\begin{tabular}{|c|c|c|c|}
\hline & All $(n=502)$ & Isolated $(n=301)$ & Quarantined $(n=20 I)$ \\
\hline CES-D, mean (SD) & $16.76(5.65)$ & $17.26(5.94)$ & $16.01(5.10)$ \\
\hline$\leq 16, \mathrm{n}(\%)$ & 297 (59.2\%) & $164(54.5 \%)$ & $133(66.2 \%)$ \\
\hline$>16, \mathrm{n}(\%)$ & 205 (40.8\%) & $137(45.5 \%)$ & $68(33.8 \%)$ \\
\hline IES-R, mean (SD) & $13.50(14.67)$ & $|4.3|(|5.5|)$ & $12.28(13.24)$ \\
\hline$<24, \mathrm{n}(\%)$ & 404 (80.5\%) & $238(79.1 \%)$ & $166(82.6 \%)$ \\
\hline 24-32, n (\%) & 37 (7.4\%) & $23(7.6 \%)$ & 14 (7.0\%) \\
\hline $33-38, \mathrm{n}(\%)$ & 24 (4.8\%) & 14 (4.7\%) & $10(5.0 \%)$ \\
\hline$\geq 39, \mathrm{n}(\%)$ & 37 (7.4\%) & $26(8.6 \%)$ & II (5.5\%) \\
\hline SS, mean (SD) & $25.29(7.99)$ & $24.23(8.06)$ & $26.87(7.63)$ \\
\hline$\leq 25, \mathrm{n}(\%)$ & $234(46.6 \%)$ & $162(53.8 \%)$ & $72(35.8 \%)$ \\
\hline$>25, \mathrm{n}(\%)$ & $268(53.4 \%)$ & $139(46.2 \%)$ & $129(64.2 \%)$ \\
\hline
\end{tabular}

Table 3 Associations between demographics and scale scores (ANOVA and t-tests)

\begin{tabular}{|c|c|c|c|c|c|c|c|}
\hline & & CES-D, mean (SD) & $P$ & IES-R, mean (SD) & $P$ & SS, mean (SD) & $P$ \\
\hline \multirow[t]{2}{*}{ Sex } & Male & $15.38(4.62)$ & \multirow[t]{2}{*}{$<0.001$} & $10.83(12.48)$ & \multirow[t]{2}{*}{$<0.001$} & $24.81(8.10)$ & \multirow[t]{2}{*}{0.184} \\
\hline & Female & $18.13(6.22)$ & & $16.15(16.15)$ & & $25.76(7.87)$ & \\
\hline \multirow[t]{6}{*}{ Occupation } & Retired & $16.13(16.13)$ & \multirow[t]{6}{*}{0.033} & $12.40(12.57)$ & \multirow[t]{6}{*}{$<0.001$} & $24.89(9.30)$ & \multirow[t]{6}{*}{0.931} \\
\hline & Employed (public) & $17.36(5.87)$ & & I5.88 (16.79) & & $25.39(7.58)$ & \\
\hline & Employed (private) & I5.6I (4.57) & & $10.32(10.97)$ & & $25.61(7.73)$ & \\
\hline & Self-employed & $15.35(5.42)$ & & $9.64(12.60)$ & & $26.03(4.68)$ & \\
\hline & Unemployed & $17.60(6.09)$ & & $|4.4|$ (I5.59) & & $25.07(8.00)$ & \\
\hline & Student & $18.00(6.89)$ & & $34.16(23.01)$ & & $27.96(4.57)$ & \\
\hline \multirow[t]{5}{*}{ Education } & Elementary or below & $15.22(4.28)$ & \multirow[t]{5}{*}{0.052} & $6.95(10.13)$ & \multirow[t]{5}{*}{0.014} & $20.75(8.00)$ & \multirow[t]{5}{*}{0.045} \\
\hline & Middle & I5.79 (5.05) & & II.7I (13.30) & & $24.57(8.88)$ & \\
\hline & High & $17.45(6.20)$ & & I5.34 (I5.69) & & $25.99(7.80)$ & \\
\hline & Undergraduate & $16.99(5.61)$ & & 14.25 (|4.9|) & & $25.10(8.30)$ & \\
\hline & Postgraduate & $15.56(4.50)$ & & $9.84(11.95)$ & & $26.04(5.88)$ & \\
\hline \multirow[t]{4}{*}{ Marital status } & Single & $16.68(5.59)$ & \multirow[t]{4}{*}{0.628} & 14.52 (I5.32) & \multirow[t]{4}{*}{0.867} & $25.81(7.15)$ & \multirow[t]{4}{*}{0.533} \\
\hline & Married & $16.76(5.64)$ & & $|3.3|(\mid 4.52)$ & & $25.22(8.11)$ & \\
\hline & Divorced & $15.28(4.64)$ & & 13.14 (15.92) & & $26.34(10.99)$ & \\
\hline & Widowed & $19.00(7.78)$ & & $11.12(15.46)$ & & $21.66(8.68)$ & \\
\hline
\end{tabular}

\section{Discussion}

This was a cross sectional retrospective cohort study involving 502 participants selected randomly from the Ministry of Health database to explore the impact of COVID-19 isolation and quarantine. We used validated and translated tools to measure depression, distress, and perceived stigma associated with the pandemic. About $40 \%$ of participants showed clinically significant depression, with those isolated exhibiting greater depression than those quarantined. Less than $20 \%$ had indications of distress, with greater distress in those isolated than those quarantined. Distress and diagnosis of PTSD were also more pronounced in 
Table 4 Associations between clinical variables and scale scores (ANOVA and $t$-tests)

\begin{tabular}{|c|c|c|c|c|c|c|c|}
\hline & & $\begin{array}{l}\text { CES-D, ean } \\
\text { (SD) }\end{array}$ & $P$ & $\begin{array}{l}\text { IES-R, mean } \\
\text { (SD) }\end{array}$ & $P$ & $\begin{array}{l}\text { SS, mean } \\
\text { (SD) }\end{array}$ & $P$ \\
\hline \multirow[t]{3}{*}{ Smoking status } & Smoker & $15.65(4.26)$ & \multirow[t]{3}{*}{0.040} & I 2.07 (| 3.08$)$ & \multirow[t]{3}{*}{0.410} & $24.70(8.11)$ & \multirow[t]{3}{*}{0.315} \\
\hline & Nonsmoker & $|6.9|(5.85)$ & & $13.66(14.75)$ & & $25.60(7.85)$ & \\
\hline & Ex-smoker & $18.15(6.37)$ & & I5.6I (I7.49) & & $23.87(8.88)$ & \\
\hline \multirow[t]{2}{*}{ History of mental conditions } & Yes & $24.07(8.97)$ & \multirow[t]{2}{*}{$<0.001$} & $26.71(18.78)$ & \multirow[t]{2}{*}{$<0.001$} & $29.20(9.64)$ & \multirow[t]{2}{*}{0.063} \\
\hline & No & $16.55(5.39)$ & & $13.12(14.38)$ & & $25.18(7.92)$ & \\
\hline \multirow[t]{4}{*}{ Place of segregation } & Home & $16.06(4.95)$ & \multirow[t]{4}{*}{0.008} & $12.57(14.17)$ & \multirow[t]{4}{*}{0.255} & $26.09(7.31)$ & \multirow[t]{4}{*}{0.010} \\
\hline & Isolation facility & $|7.6|(5.90)$ & & $14.06(14.19)$ & & $25.09(7.40)$ & \\
\hline & Hospital & $18.08(7.15)$ & & $|5.5|(16.34)$ & & $22.85(9.81)$ & \\
\hline & $\mathrm{ICU}$ & $16.85(4.18)$ & & $19.14(19.20)$ & & $25.23(13.14)$ & \\
\hline \multirow{3}{*}{$\begin{array}{l}\text { Having transmitted } \\
\text { COVID-19 }\end{array}$} & Yes & $|8.7|(5.84)$ & \multirow[t]{3}{*}{0.003} & $14.8 \mid(16.10)$ & \multirow[t]{3}{*}{0.300} & $24.52(7.10)$ & \multirow[t]{3}{*}{$<0.001$} \\
\hline & No & $16.84(5.91)$ & & 14.17 (I5.37) & & $24.15(8.34)$ & \\
\hline & NA & $16.01(5.10)$ & & $12.28(13.24)$ & & $26.87(7.63)$ & \\
\hline \multirow[t]{4}{*}{ Difficulty returning to work } & No & $16.27(4.89)$ & \multirow[t]{4}{*}{0.004} & $12.70(14.04)$ & \multirow[t]{4}{*}{0.380} & $25.54(7.70)$ & \multirow[t]{4}{*}{0.893} \\
\hline & Yes, but returned & $19.06(8.99)$ & & $|4.8|(\mid 3.86)$ & & $24.72(9.04)$ & \\
\hline & NA & $16.89(5.87)$ & & $13.9 \mid(15.27)$ & & $25.08(8.26)$ & \\
\hline & Yes, but lost job & $23.66(6.77)$ & & $22.16(12.89)$ & & $26.48(4.73)$ & \\
\hline \multirow[t]{2}{*}{ Social conflict or breakups } & Yes & $20.8 I(6.7 I)$ & \multirow[t]{2}{*}{$<0.001$} & $21.27(19.03)$ & \multirow[t]{2}{*}{$<0.001$} & $28.22(8.50)$ & \multirow[t]{2}{*}{0.020} \\
\hline & No & $16.44(5.44)$ & & $12.88(14.11)$ & & $25.06(7.91)$ & \\
\hline \multirow{2}{*}{$\begin{array}{l}\text { Knowing a fatality due to COVID- } \\
19\end{array}$} & No & $16.32(5.26)$ & \multirow[t]{2}{*}{$<0.001$} & $12.86(14.38)$ & \multirow[t]{2}{*}{0.029} & $25.16(8.07)$ & \multirow[t]{2}{*}{0.428} \\
\hline & Yes & $|8.9|(6.91)$ & & $16.67(15.71)$ & & $25.92(7.58)$ & \\
\hline \multirow[t]{2}{*}{ COVID-19 status } & Isolated & $17.26(5.94)$ & \multirow[t]{2}{*}{0.015} & $|4.3|(|5.5|)$ & \multirow[t]{2}{*}{0.129} & $24.23(8.06)$ & \multirow[t]{2}{*}{0.001} \\
\hline & Quarantined & $16.01(5.10)$ & & $12.28(13.24)$ & & $26.87(7.63)$ & \\
\hline \multirow[t]{2}{*}{ Recruitment status } & Early & $16.66(5.52)$ & 0.731 & |3.5| (13.97) & $0.78 \mathrm{I}$ & $25.4 \mathrm{I}(8.99)$ & 0.991 \\
\hline & Late & $16.83(5.74)$ & & $13.50(15.13)$ & & $25.21(7.26)$ & \\
\hline
\end{tabular}

Table 5 Correlations between age, duration of isolation and scale scores

\begin{tabular}{|l|l|l|l|l|}
\hline & Age, $(\boldsymbol{r})$ & $\boldsymbol{P}$ & Duration of Segregation, $(\boldsymbol{r})$ & $\boldsymbol{P}$ \\
\hline CES-D & -0.097 & 0.030 & 0.165 & $<0.00 \mathrm{I}$ \\
\hline IES-R & -0.184 & $<0.001$ & 0.056 & 0.206 \\
\hline SS & -0.149 & 0.001 & -0.082 & 0.065 \\
\hline
\end{tabular}

participants that had undergone isolation. Perceived stigma was more prominent among those quarantined than those placed in isolation. This is higher than that reported among the general population in Bahrain during the pandemic, with about a third reporting depressive and stress symptoms, ${ }^{26}$ but similar to ta study on the general 
Table 6 Effect of sociodemographic characteristics on indices of mental health*

\begin{tabular}{|c|c|c|c|c|c|c|}
\hline & \multicolumn{2}{|c|}{ CES-D (adjusted $R^{2}=0.114$ ) } & \multicolumn{2}{|l|}{ IES-R (adjusted $R^{2}=0.086$ ) } & \multicolumn{2}{|l|}{ SS (adjusted $R^{2}=0.046$ ) } \\
\hline & Coefficient $(95 \% \mathrm{Cl})$ & $P$ & Coefficient $(95 \% \mathrm{Cl})$ & $\boldsymbol{P}$ & Coefficient $(95 \% \mathrm{CI})$ & $\boldsymbol{P}$ \\
\hline Age & $-0.055(-0.093$ to -0.016$)$ & 0.006 & $-0.223(-0.325$ to -0.121$)$ & $<0.001$ & $-0.078(-0.135$ to -0.021$)$ & 0.007 \\
\hline Sex & $2.700(1.631$ to 3.770$)$ & $<0.001$ & $5.297(2.477$ to 8.116$)$ & $<0.001$ & $0.898(-0.67 \mid$ to 2.467$)$ & 0.261 \\
\hline Education & $-0.067(-0.522$ to 0.387$)$ & 0.771 & $-0.352(-1.55$ I to 0.846$)$ & 0.564 & 0.271 ( -0.396 to 0.938$)$ & 0.426 \\
\hline Occupation & $-0.186(-0.535$ to 0.163$)$ & 0.296 & $-0.343(-1.263$ to 0.578$)$ & 0.465 & $-0.058(-0.570$ to 0.454$)$ & 0.825 \\
\hline Marital status & $0.373(-0.755$ to I.50I) & 0.516 & $0.688(-2.285$ to $3.66 \mathrm{I})$ & 0.650 & $0.126(-1.528$ to 1.780$)$ & 0.881 \\
\hline History of mental illness & $-7.019(-9.898$ to -4.140$)$ & $<0.001$ & $-13.467(-21.056$ to -5.877$)$ & 0.001 & $-4.422(-8.645$ to -0.199$)$ & 0.040 \\
\hline COVID-19 status & $-1.333(-2.290$ to 0.375$)$ & 0.006 & -2.34 I ( -4.865 to 0.184$)$ & 0.069 & 2.462 (1.058 to 3.867$)$ & 0.001 \\
\hline
\end{tabular}

Note: *Values are unstandardized coefficients from multivariate regression.

population from Saudi Arabia, both studies utilizing a snowball social media-sampling technique. ${ }^{27}$

Social stigma and discrimination have been described in detail in other infectious respiratory diseases, such as tuberculosis, SARS, and MERS-CoV. ${ }^{28}$ Stigmatizing language, eg, "tuberculosis suspect," has been criticized by activists, as well as "COVID-19 suspect."29 COVID-19 cases and close contacts have been compared to criminals. $^{29}$ Stigma toward those who have recovered from COVID-19, undergoing treatment, or presumed to be affected has been well described in the literature, especially in developing countries. ${ }^{30}$

Although most reports have indicated that men with COVID-19 have a poorer prognosis, there is an increasing body of evidence to confirm that the psychological impact is more profound in women. ${ }^{26,27,30,31}$ This agrees with our results, which showed that females exhibited more psychological depression and distress. College students were the most affected among occupational categories in this study. Although the number of college students that participated in this study was low, this result is consistent with other studies reporting that the mental health of college students has been significantly affected during the COVID-19 pandemic. ${ }^{26,27,32,33}$ Concerns of personal health, health of family members, and finance, particularly for those impacted by prolonged closure of employers, have been reported. ${ }^{34}$ The added impact of quarantine has led to high occurrence of distress, depression, anxiety, stress, and even self-reported suicidal thoughts. ${ }^{33}$ Loss of income, poor-quality housing, history of psychiatric follow-up, symptoms compatible with COVID-19, low levels of physical activity, not living with family, weak sense of integration, low quality of social relations, and receiving low-quality information were associated with all mental health issues. ${ }^{33}$ Consistently with a recent systematic review, our findings suggested that people with preexisting mental conditions are at highest risk of psychological distress and should be targeted for psychological assessment and appropriate intervention. ${ }^{31}$ Based on the results of this study and others, female college students with mental health conditions may be particularly vulnerable to psychological impact due to isolation and quarantine. Given the immediate and long-lasting effects, such groups must be the focus of psychological screening, intervention, and future research.

Not surprisingly, hospital isolation was more depressing than home isolation. The opposite, however, was true for stigmatization. It is evident from the literature that those with infectious disease have fears of infecting others during quarantine. ${ }^{5}$ Fear of infecting others or becoming infected, potentially exacerbated by ignorance of infection transmission, may have resulted in avoidance within the home beyond required social distancing measures. Such experiences of avoidance from family members, as opposed to trained healthcare professionals, may have led to feelings of great hurt and shame, increasing the burden of stigma. Other contributing factors were losing one's job, experiencing social conflict or breakup, transmitting the infection to others, or knowing someone who had died due to the disease. Duration between isolation/quarantine and interview did not have a significant effect on psychological outcomes, which could reflect the longlasting effect of segregation. In one study, alcohol abuse and dependence symptoms were reported among quarantined individuals 3 years after the SARS outbreak. ${ }^{35}$ 
One of the strengths of this study was the use of generic validated tools to measure depression, distress, and perceived stigma, which objectified outcome assessment and allowed fair comparisons. The three scales showed high reliability and internal consistency of $\alpha=0.7-0.9$. Further, this is one of the few studies in the region describing the psychological impact of COVID-19 for cases (isolated) and contacts (quarantined) at two times of segregation. However, this study is not without limitations. Due to the escalating nature of this pandemic, we were unable to compare psychological outcomes immediately after quarantine/isolation (baseline) and months later among the same cohort. Instead, we recruited two groups at two stages of segregation and compared outcomes. These selected periods might not be representative of the whole period. Another limitation was that we did not capture psychological effects related to travel for religious purposes, which was perceived as a threat in terms ofspreading the infection, ultimately resulting in government-led repatriation.

\section{Conclusion}

This study identified high-risk populations and risk factors of higher psychological distress that could be used for risk stratification and the design of effective psychological interventions at both clinical and community levels. Additionally, the findings underscore the importance of implementation and rollout of psychological services and intervention programs. Like most countries, Bahrain is currently prioritizing medical resources for the containment of COVID-19 and the treatment of patients with COVID-19, and hence there may be limited resources available for psychological services and interventions. Therefore, improving knowledge, awareness, and self-coping strategies are critical in this situation. In conclusion, the COVID-19 pandemic has caused unprecedented psychological impact among the general population. Psychological interventions identifying and targeting people with different-severity psychological burdens are urgently needed.

\section{Data Sharing Statement}

The data sets used and/or analyzed during the current study are available from the corresponding author on reasonable request.

\section{Ethics Approval and Consent to Participate}

The study was conducted in accordance with the Declaration of Helsinki and approved by the National
COVID-19 Research and Ethics Committee and the Royal College of Surgeons in Ireland - Medical University of Bahrain's ethics committee. All participants were adequately informed about the study and consented to participation. Participation was voluntary and data anonymous and dealt with confidentially.

\section{Acknowledgments}

We are extremely grateful to all participants for their valuable participation at this difficult time.

\section{Author Contributions}

All authors made substantial contributions to conception and design, acquisition of data, or analysis and interpretation of data, took part in drafting the article or revising it critically for important intellectual content, agreed to submit to the current journal, gave final approval to the version to be published, and agree to be accountable for all aspects of the work.

\section{Disclosure}

The authors declare that they have no competing interests.

\section{References}

1. WHO. Considerations for quarantine of individuals in the context of containment for coronavirus disease (COVID-19); 2020. Available from: file:///C:/Users/gjassim/Downloads/20200229-covid-19quarantine.pdf.

2. MOH. Coronavirus (COVID-19) latest updates; 2020. Available from: https://www.moh.gov.bh/COVID19/Details/3926. Accessed April 29, 2021.

3. WHO. World Health Organization. Global surveillance for human infection with coronavirus disease (COVID-19); 2020. Available from: https://www.who.int/publications-detail/global-surveillance-forhuman-infection-with-novel-coronavirus-(2019-ncov). Accessed April 29, 2021.

4. Füzéki E, Groneberg DA, Banzer W. Physical activity during COVID-19 induced lockdown: recommendations. J Occup Med Toxicol. 2020;15(1):25. doi:10.1186/s12995-020-00278-9

5. Brooks S, Webster B, Smith L, et al. The psychological impact of quarantine and how to reduce it: rapid review of the evidence. Lancet. 2020;395(10227):912-920. doi:10.1016/S0140-6736(20)30460-8

6. Almutairi AF, Adlan AA, Balkhy HH, Abbas OA, Clark AM. "It feels like I'm the dirtiest person in the world.": exploring the experiences of healthcare providers who survived MERS-CoV in Saudi Arabia. $J$ Infect Public Health. 2018;11(2):187-191. doi:10.1016/j. jiph.2017.06.011

7. Mak WW, Cheung F, Woo J, et al. A comparative study of the stigma associated with infectious diseases (SARS, AIDS, TB). Hong Kong Med J. 2009;15(Suppl 8):34-37.

8. Siu JY. The SARS-associated stigma of SARS victims in the post-SARS era of Hong Kong. Qual Health Res. 2008;18 (6):729-738. doi:10.1177/1049732308318372

9. Lee S, Chan LY, Chau AM, Kwok KP, Kleinman A. The experience of SARS-related stigma at Amoy Gardens. Soc Sci Med. 2005;61 (9):2038-2046. doi:10.1016/j.socscimed.2005.04.010 
10. Li J, Yang Z, Qiu H, et al. Anxiety and depression among general population in China at the peak of the COVID-19 epidemic. World Psychiatry. 2020;19(2):249-250. doi:10.1002/wps.20758

11. Qiu J, Shen B, Zhao M, Wang Z, Xie B, Xu Y. A nationwide survey of psychological distress among Chinese people in the COVID-19 epidemic: implications and policy recommendations. Gen Psychiatry. 2020;33(2):e100213. doi:10.1136/gpsych-2020-100213

12. Olff M, Bakker A, Frewen P, et al. Screening for consequences of trauma - an update on the global collaboration on traumatic stress. Eur J Psychotraumatol. 2020;11(1):1752504. doi:10.1080/2000819 8.2020.1752504

13. Rossi R, Socci V, Talevi D, et al. COVID-19 pandemic and lockdown measures impact on mental health among the general population in Italy. Front Psychiatry. 2020;11:790. doi:10.3389/fpsyt.2020.00790

14. Dsouza DD, Quadros S, Hyderabadwala ZJ, Mamun MA. Aggregated COVID-19 suicide incidences in India: fear of COVID-19 infection is the prominent causative factor. Psychiatry Res. 2020;290:113145. doi:10.1016/j.psychres.2020.113145

15. Mamun MA, Griffiths MD. First COVID-19 suicide case in Bangladesh due to fear of COVID-19 and xenophobia: possible suicide prevention strategies. Asian J Psychiatr. 2020;51:102073. doi:10.1016/j.ajp.2020.102073

16. IBBAf. Available from: https://apps.bahrain.bh/ CMSWebApplication/action/ShowAppDetails Action? selectedAppID=321\&appLanguage=en. Accessed April 29, 2021.

17. Radloff LS. The CES-D Scale: A Self-Report Depression Scale for Research in the General Population; 1977.

18. Boyd JH, Weissman MM, Thompson WD, Myers JK. Screening for depression in a community sample: understanding the discrepancies between depression symptom and diagnostic scales. Arch Gen Psychiatry. 1982;39(10):1195-1200. doi:10.1001/archpsyc.1982.04 290100059010

19. Weiss D. The Impact of Event Scale-revised. New York: Guilford; 1997.

20. Asukai N, Kato H, Kawamura N, et al. Reliability and validity of the Japanese-language version of the impact of event scale-revised (IES-R-J): four studies of different traumatic events. J Nerv Ment Dis. 2002;190(3):175-182. doi:10.1097/00005053-200203000-00006

21. Creamer M, Bell R, Failla S. Psychometric properties of the impact of event scale - revised. Behav Res Ther. 2003;41(12):1489-1496. doi:10.1016/j.brat.2003.07.010

22. Kawamura N, Kim Y, Asukai N. Suppression of cellular immunity in men with a past history of posttraumatic stress disorder. Am J Psychiatry. 2001;158(3):484-486. doi:10.1176/appi.ajp.158.3.484

23. Van Rie A, Sengupta S, Pungrassami P, et al. Measuring stigma associated with tuberculosis and HIV/AIDS in southern Thailand: exploratory and confirmatory factor analyses of two new scales. Trop Med Int Health. 2008;13(1):21-30. doi:10.1111/j.13653156.2007.01971.x
24. Kazarian S, Taher D. Validation of the Arabic Center for Epidemiological Studies Depression (CES-D) Scale in a Lebanese Community Sample. Eur J Psychol Assess. 2010;26:68-73. doi:10.1027/1015-5759/a000010

25. Yousef H, Alharthi S, Alzahrani A. ARTICLE Reliability and Validity of Arabic Translation of the Impact of Event Scale-Revised for COVID-19 Pandemic Medical Science. 2020;24.

26. Alsalman A, Jahrami H, Mubarak H, et al. The psychological impact of COVID-19 Pandemic on the population of Bahrain: prevalence and Comparison study. Acta Biomed. 2020;91(4):e2020131. doi:10.23750/abm.v91i4.10336

27. Alkhamees AA, Alrashed SA, Alzunaydi AA, Almohimeed AS, Aljohani MS. The psychological impact of COVID-19 pandemic on the general population of Saudi Arabia. Compr Psychiatry. 2020;102:152192. doi:10.1016/j.comppsych.2020.152192

28. Daftary A. HIV and tuberculosis: the construction and management of double stigma. Soc Sci Med. 2012;74(10):1512-1519. doi:10.1016/ j.socscimed.2012.01.027

29. Sotgiu G, Dobler CC. Social stigma in the time of coronavirus disease 2019. Eur Respir J. 2020;56(2):2002461. doi:10.1183/ 13993003.02461-2020

30. Burki T. The indirect impact of COVID-19 on women. Lancet Infect Dis. 2020;20(8):904-905. doi:10.1016/S1473-3099(20)30568-5

31. Luo M, Guo L, Yu M, Jiang W, Wang H. The psychological and mental impact of coronavirus disease 2019 (COVID-19) on medical staff and general public - a systematic review and meta-analysis. Psychiatry Res. 2020;291:113190. doi:10.1016/j.psychres.20 20.113190

32. Cao W, Fang Z, Hou G, et al. The psychological impact of the COVID-19 epidemic on college students in China. Psychiatry Res. 2020;287:112934. doi:10.1016/j.psychres.2020.112934

33. Wathelet M, Duhem S, Vaiva G, et al. Factors associated with mental health disorders among university students in france confined during the COVID-19 pandemic. JAMA Netw Open. 2020;3(10):e2025591e2025591. doi:10.1001/jamanetworkopen.2020.25591

34. Kecojevic A, Basch CH, Sullivan M, Davi NK. The impact of the COVID-19 epidemic on mental health of undergraduate students in New Jersey, cross-sectional study. PLoS One. 2020;15(9):e0239696. doi:10.1371/journal.pone.0239696

35. Wu P, Liu X, Fang Y, et al. Alcohol abuse/dependence symptoms among hospital employees exposed to a SARS outbreak. Alcohol Alcohol. 2008;43(6):706-712. doi:10.1093/alcalc/agn073
Neuropsychiatric Disease and Treatment

\section{Publish your work in this journal}

Neuropsychiatric Disease and Treatment is an international, peerreviewed journal of clinical therapeutics and pharmacology focusing on concise rapid reporting of clinical or pre-clinical studies on a range of neuropsychiatric and neurological disorders. This journal is indexed on PubMed Central, the 'PsycINFO' database and CAS, an is the official journal of The International Neuropsychiatric Association (INA). The manuscript management system is completely online and includes a very quick and fair peer-review system, which is all easy to use. Visit http://www.dovepress.com/testimonials.php to read real quotes from published authors. 